\title{
Etiology and Frequency of Self-Report Pain in Women with Breast Cancer
}

\author{
Christina Guimarães Ribeiro Soares ${ }^{1}$, William Giovanni Panfiglio Soares ${ }^{2}$, \\ Mariana Tirolli Rett ${ }^{3}$, Débora Moura Da Paixão Oliveira ${ }^{4}$, Marco Antonio Prado \\ Nunes $^{5}$, Carlos Umberto Pereira ${ }^{6}$, Simone Yuriko Kameo ${ }^{7}$ \\ ${ }^{1}$ Nurse. University Hospital of Sergipe. Aracaju, Sergipe, Brazil; \\ ${ }^{2}$ Physician. Federal University of Sergipe. Aracaju, Sergipe, Brazil; \\ ${ }^{3}$ Physiotherapist. Federal University of Sergipe, Aracaju, Sergipe, Brazil; \\ ${ }^{4}$ Nurse. Federal University of Sergipe, Aracaju, Sergipe, Brazil; \\ ${ }^{5}$ Physician. Federal University of Sergipe. Aracaju, Sergipe, Brazil; \\ ${ }^{6}$ Physician. Federal University of Sergipe. Aracaju, Sergipe, Brazil; \\ ${ }^{7}$ Nurse. Federal University of Sergipe, Lagarto, Sergipe, Brazil.
}

\begin{abstract}
Breast cancer is the most common cancer among women and the manifestation of pain is frequent, can occur at all stages of the disease, as well as being a consequence of various diagnostics and therapeutics approaches. The aim was to describe the pain in breast cancer women and its relation to the disease, report the main anatomical sites of pain, identify the occurrence of pain in the last 24 hours and check the intensity of pain related or unrelated to breast cancer. A descriptive study involving outpatient women diagnosed with breast cancer at any stage of the disease or treatment, from November 2011 to April 2012. The interviews were conducted with the oncology outpatients from Hospital Urgencies of Sergipe, using a screening questionnaire elaborated by the researchers and the Brief Pain Inventory (BPI). As results, 90 women aged 27-80 years old were interviewed, $59(66 \%)$ did not relate the pain with breast cancer and $73(81 \%)$ reported no pain before the illness. Only 34 women (38\%) reported pain in the last 24 hours negatively affecting the ability to walk, sleep and mood. The average pain on a scale from 0 to 10 was 4.8. The major anatomical sites of pain were the upper extremities (23\%), lower limbs (21\%) and spine (15\%). Fifty-nine (66\%) of the women interviewed did not relate pain with breast cancer, highlighting the upper extremities as major anatomical sites of pain. The pain was present, in the last 24 hours, in 38\% of women, in mild intensity and interfering with quality of life.
\end{abstract}

Keywords: Breast neoplasms, self-report, pain, pain measurement.

\section{Introduction}

Breast cancer is the type of cancer with the highest incidence among women. In Brazil, it is the leading cause of death from malignant diseases. Each year, about $20 \%$ of new cancer cases in women are breast cancer and it is estimated to 2016/2017 the appearance of 57.960 new cases [1]. Despite advances in diagnosis and treatment of malignant neoplasm of the breast, surgical interventions are the techniques used further. Among the complementary therapies for the treatment of breast cancer, some are used: chemotherapy, radiotherapy and hormonal therapy, which can be used in neoadjuvant way, adjuvant or palliative [2-3].

Although the therapeutic approach to breast cancer brings many benefits, there may be immediate or late complications, and pain as a common symptom. Pain can be defined as an unpleasant sensory and emotional experience, which may or may not be associated with tissue damage [2,4]. The fact that pain is a subjective and individual phenomenon, involving the physical, mental and emotional [5-6], can often make it be misunderstood and underestimated [7].

The measurement of pain in cancer patients can be carried out by one-dimensional and multidimensional instruments and so, depending on the test and instrument, cancer pain may occur in about $50 \%$ of patients with early-stage cancer and in $90 \%$ of those with advanced disease [8-9]. It is noteworthy that about $80 \%$ of cancer patients present pain at some point of the disease [10].

It is important to determine the cause of pain, or to identify its presence or if the pain are not related to cancer [11-12]. Pain of cancer patients may be associated with multiple etiologies, directly or indirectly related to the organ affected by the primary tumor and its metastases, the antineoplastic therapy and investigative methods (biopsies and tests related) or may not be associated to the cancer.

Given this context, the aim of this study is to check whether there is a relationship between breast cancer and cancer pain, and describe the main anatomical sites of pain, the occurrence of pain in the last 24 hours and its relation or not to breast cancer. 


\section{Materials and Method}

A descriptive, quantitative study, was conducted at the Hospital Urgencies of Sergipe (HUSE) in the Oncology Clinic, in a period from November 2011 to April 2012. The study was approved by the Research Ethics Committee of the Federal University of Sergipe (UFS) as paragraph CAAE: 0552.0.000.107-11. Participants signed the Informed Consent (IC), ensuring the ethical aspects set out in Decree 196/96 of the National Council of Health of Ministry of Health.

The sample size was calculated based on the prevalence of pain in $44 \%$ of women with breast cancer [11], with test power of $80 \%$ and a significance level of 5\%. They included 90 women diagnosed with breast cancer in outpatient treatment, with communication skills and understanding preserved.

A standardized interview technique to collect personal, clinical and pain data was used. To measure the pain, the Brief Pain Inventory (BPI) was used. It is an instrument composed of 15 items, divided into two parts: first, evaluate the location and intensity of pain in 8 questions. The location is indicated by the women in a body chart and the intensity of pain is assessed by the patient with reference the last 24 hours on a numerical scale from 0 to 10 , where 0 is no pain and 10 is the most severe pain. The second part evaluates the interference of pain related to the life of the patient as general activity, sleep, mood, ability to walk, work, way to enjoy life and relationships with people. The pain interference is also evaluated using numeric scale of 0 to 10 where 0 represents no pain interference and 10 shows the pain interferes completely in some aspects of life of patients [13]. To evaluate the relationship of pain with cancer, we used the chi-square test of Pearson and Fisher exact, the Mac Excel 2011 and SPSS (Statistical Package for Social Sciences) version 20 demo.

\section{Results}

The sample included 90 women. The age ranged from 27 to 80 years old, mean of $49.0( \pm 10.2)$ years old. Regarding ethnicity, $64(71 \%)$ were white, $58(64 \%)$ had no partners and the predominant religion was Catholic (67\%). More than half, $46(51 \%)$ attended to the primary school and most on leave from work for own health. The average time of diagnosis was $31.9( \pm 34.4)$ months and ten women had metastasis (Table 1).

Table 1. Personal and clinical characteristics of women with breast cancer $(n=90)$. Aracaju, Sergipe, Brazil.

\begin{tabular}{|c|c|c|}
\hline \multicolumn{2}{|c|}{ Characteristics } & $\mathrm{N}(\%)$ \\
\hline \multicolumn{2}{|l|}{ Age } & $49.0 *( \pm 10.2)$ \\
\hline \multicolumn{2}{|c|}{ Diagnostic time (months) } & $31.9 *( \pm 34.4)$ \\
\hline \multicolumn{3}{|c|}{ Ethnicity } \\
\hline & White & $26(29)$ \\
\hline & Others & $64(71)$ \\
\hline \multicolumn{3}{|c|}{ Marital Status } \\
\hline & With partner & $32(36)$ \\
\hline & No partner & $58(64)$ \\
\hline \multicolumn{3}{|l|}{ Religion } \\
\hline & Catholic & $60(67)$ \\
\hline & Spiritualist & $6(7)$ \\
\hline & Evangelical & $23(26)$ \\
\hline & Other & $1(1)$ \\
\hline \multicolumn{3}{|l|}{ Education } \\
\hline & No schooling & $4(4)$ \\
\hline & Incomplete primary & $3(3)$ \\
\hline & Elementary school & $46(51)$ \\
\hline & High school & $22(24)$ \\
\hline & Graduation/ Post graduation & $15(16)$ \\
\hline \multicolumn{3}{|c|}{ Work situation } \\
\hline & Retired & $16(18)$ \\
\hline & Autonomous & $10(11)$ \\
\hline & Without job & $15(17)$ \\
\hline & Housekeeper & $10(11)$ \\
\hline & Sick leave & $39(43)$ \\
\hline \multirow[t]{2}{*}{ Metastasis } & Yes & $10(11)$ \\
\hline & No & $80(89)$ \\
\hline
\end{tabular}

* Expressed as mean values ( \pm standard deviation) absolute value $(\%)$.

Related to pain, there was a higher proportion of women $73(81 \%)$ who felt no pain before the diagnosis of cancer. When asked about their pain, $59(66 \%)$ women did not related pain to cancer. Regardless of pain etiology, more than half of the sample $56(62 \%)$ did not report pain in the last 24 hours (Table 2).

Table 2. Frequency of pain reported by women with breast cancer $(\mathrm{n}=90)$. Aracaju, Sergipe, Brazil.

\begin{tabular}{|l|l|l|}
\hline Data on pain & & $\mathrm{n}(\%)$ \\
\hline Pain related to disease & Yes & $31(34)$ \\
\hline
\end{tabular}




\begin{tabular}{|l|l|l|}
\hline & No & $59(66)$ \\
\hline Feel pain before cancer & Yes & $17(19)$ \\
\hline & No & $73(81)$ \\
\hline Pain in the last 24 hours & Yes & $34(38)$ \\
\hline & No & $56(62)$ \\
\hline
\end{tabular}

Among the 34 women $(31 \%)$ who reported pain in the last 24 hours, the average worst pain was $6.2( \pm$ 2.6). Moreover, the pain was responsible for greater interference in the ability to walk, sleep and mood (Table $3)$.

Table 3. Intensity and interference of pain in the last 24 hours $(n=34)$. Aracaju, Sergipe, Brazil.

\begin{tabular}{|l|l|}
\hline Data on pain & \multicolumn{1}{|c|}{ Mean $( \pm$ standard deviation $)$} \\
\hline Worst pain in the last 24 hours & $6.2( \pm 2.6)$ \\
\hline Weaker pain you felt in the past 24 hours & $2.4( \pm 2.0)$ \\
\hline Average pain & $4.8( \pm 2.0)$ \\
\hline How much pain is now & $3.9( \pm 2.8)$ \\
\hline As the pain interfered in last 24 hours & \\
\hline Overall activity & $3.9( \pm 4.0)$ \\
\hline Humor & $5.0( \pm 3.9)$ \\
\hline Ability to walk & $5.7( \pm 4.0)$ \\
\hline Work & $2.8( \pm 4.0)$ \\
\hline Relationships with others & $3.9( \pm 4.0)$ \\
\hline Sleep & $5.6( \pm 4.0)$ \\
\hline Enjoy life & $2.2( \pm 3.7)$ \\
\hline
\end{tabular}

There was no significant difference in self-reported pain related to disease in those women with metastasis and without metastasis. Similarly, there was no significant difference between those women who had pain or not before the cancer. However, the presence of pain in the 24 hours was significant among women who have related pain to cancer (Table 4$)$.

Table 4. Relationship between pain and other factors $(n=90)$. Aracaju, Sergipe, Brazil.

\begin{tabular}{|c|l|l|l|l|}
\hline \multirow{2}{*}{} & \multicolumn{3}{|l|}{ Pain related to disease } & P - value \\
\cline { 2 - 4 } & Yes & No & Total & \\
\hline Metastasis & & & & \\
\hline Yes & $4(13 \%)$ & $6(10 \%)$ & $10(11 \%)$ & \multirow{2}{*}{0.695} \\
\hline No & $27(87 \%)$ & $53(90 \%)$ & $80(89 \%)$ & \\
\hline Feel pain before cancer & & & & \\
\hline Yes & $9(29 \%)$ & $8(14 \%)$ & $17(19 \%)$ & \multirow{2}{*}{0.075} \\
\hline No & $22(71 \%)$ & $51(86 \%)$ & $73(81 \%)$ & \\
\hline Pain in the last 24 hours & & & & \\
\hline Yes & $22(69 \%)$ & $12(20 \%)$ & $34(38 \%)$ & \multirow{2}{*}{0.001} \\
\hline No & $10(31 \%)$ & $47(80 \%)$ & $57(62 \%)$ & \\
\hline
\end{tabular}

In the body diagram, the patients showed main anatomical sites of pain upper limbs (UL), followed by the lower limbs (LL) and spinal column, with 23\%, 21\% and 15\% respectively (Figure 1).

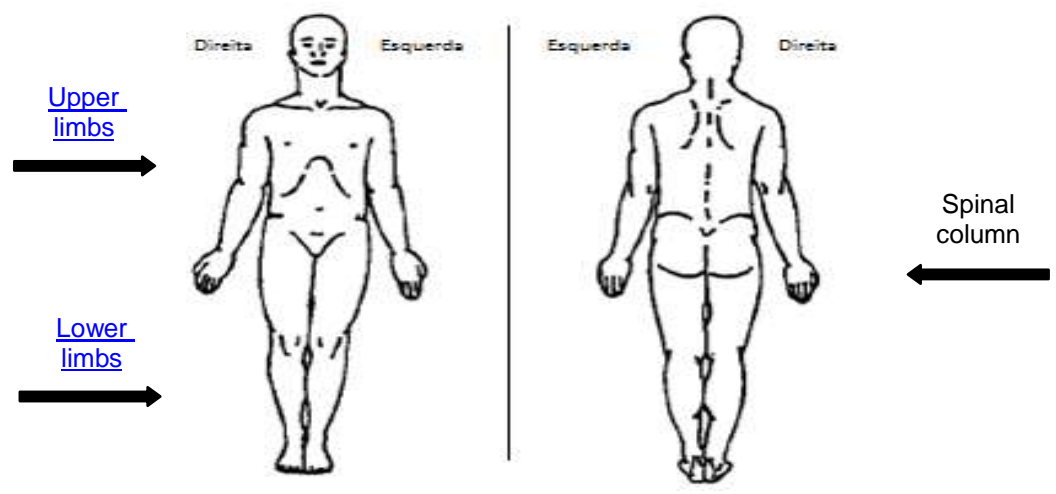

Figure 1. Body Diagram representing the anatomical sites of pain $(n=34)$.

\section{Discussion}

Pain is a frequent event in patients with malignancies and can be modified in the face of therapeutic or disease progression $[9,12,14]$. The perception and response to pain vary among patients with the same disease 
that have equal length and location, leading to different pain intensities. These individual differences may be related to gender, race, education, family history and also the emotional experiences and feelings that directly influence the painful sensation [5.15].

In this study the average age of women with breast cancer was 49 years old, representing a young population compared to the values found in the literature, in which the average age is 61 years old [16]. Most women were nonwhite race, and there was no significant difference between race and presence of pain. However, the literature indicates that nonwhite were twice as likely to feel more pain and the age and educational level were not associated with pain [6]. Among the women studied, the prevalence of pain was higher in those with low education, probably for fear of dependence on drugs used for analgesia. Some authors found that low or medium level of education was related to a significantly higher risk of pain compared to patients with higher level of education [14].

The prevalence of cancer pain can vary from $53 \%$ to $60 \%[11,14,17]$ and in women with breast cancer from $23 \%$ to $47 \%[11,18]$. While many studies show high prevalence of pain among cancer patients $[12,14,17]$, this study found through the report of the majority of women that the presence of pain was not related to breast cancer.

Draws attention, the fact that most women have no pain related to cancer, data consonants to another study in which it was observed that females attributed the pain to a greater extent of factors unrelated to cancer [11]. This can be hypothesized by the fact that women show more resilience to situations that cause pain and suffering, experienced situations such as labor and delivery, breastfeeding, which are inherent to the female gender, may have contributed to a different perception of pain intensity.

On the other hand, some studies have shown a higher prevalence of pain and increased sensitivity among women than men. In addition, sex hormones also affect the pain sensitivity threshold and pain tolerance. Many states of chronic pain are more frequent and more aggressive in women, such as migraine, rheumatic pain and cardiology. Still, the response to opioid analgesics, and also shows difference when related to the genre [19].

A recent cohort study of patients with advanced cancer found that pain was not restricted to specific tumors and no difference was found between the prevalence of pain with the type of tumor [20]. However there are reports of high prevalence of moderate and severe pain in patients undergoing cancer treatment with head and neck cancer, gastrointestinal and breast [21]. Another author, previous years, also noted that patients with gastrointestinal cancer, lung, breast and hematological had a higher incidence of moderate to severe pain [14].

As this study involved only women with breast cancer and most of them had undergone surgical treatment, it is expected more frequent pain in the upper limbs. This is due to factors related to surgery, such as axillary lymphadenectomy, intercostal nerve injury, lymphatic alterations and extension of the scar [22].

Although most women have no pain related to cancer, those who reported pain in the last 24 hours, the average of this pain interfered negatively on the ability to walk, sleep and mood. A recent study showed that $75 \%$ of patients reported difficulty falling asleep or staying asleep and $19 \%$ had insomnia, and these difficulties could exist before the disease and have exacerbated after the diagnosis of cancer [23]. Sleep disorders are common in patients with cancer and are present in 30\% to 50\% of patients with breast cancer, and, insomnia a common complaint [24].

Another study, also using BPI, noted that the interference of pain in women living functions with breast cancer was small and the interference in the mood the most affected [25]. Moreover, the literature indicates that the intensity of pain can vary across the realization of complementary therapies [25], but as in the present study was not considered whether the women were either not being treated with radiation or chemotherapy at the time of interview, are limited inferences.

We suggest conducting further research to address the reasons for women with breast cancer refer more pain unrelated to cancer and its mechanisms, as well as a multidisciplinary assessment of the treatment of nonmalignant pain in order to improve the quality of life of patients.

However, better survival rates in patients with breast cancer have been observed in recent years. Although most women with this disease have a favorable prognosis, the disease and its treatment are associated with debilitating symptoms [21].

\section{Conclusion}

More than half of the women interviewed did not relate pain with breast cancer. During the last 24 hours, the pain was present in $38 \%$, negatively interfering with the ability to walk and sleep, and were located mainly in the upper limbs.

The identification of the profile of women undergoing outpatient cancer treatment allows to know the characteristics of this population and enable the clinical use of such data by the multidisciplinary team, encouraging the development of appropriate intervention strategies every woman in order to minimize the pain. 


\section{References}

[1]. Brasil. Ministério da Saúde. Instituto Nacional do Câncer. Estimativa 2016: incidência de câncer no Brasil. Rio de Janeiro: INCA, 2016. Disponível em http://www.inca.gov.br/bvscontrolecancer/publicacoes/edicao/Estimativa_2016.pdf Acesso em: 13 mai. 2016.

[2]. IASP. International Association for the Study of Pain. IASP taxonomy [internet]; 2011 [Acesso em: 10 dez 2012]. Disponível em: http://www.iasp-pain.org/Content/NavigationMenu/GeneralResourceLinks/PainDefinitions/default.htm.

[3]. Richie RC, Swanson JO. Breast cancer: a review of the literature. J Insur Med. 2003;35:85-101.

[4]. Sousa FAEF, Silva JA. Mensurando dor. Rev Dor. 2005;6(4):680-7.

[5]. Silva LMH, Zago MMF. O cuidado do paciente oncológico com dor crônica na ótica do enfermeiro. Rev Latino-Am. Enfermagem. 2001;9(4):44-9.

[6]. Castel LD, Abernethy AP, Li Y, Depuy V, Saville BR, Hartmann KE. Hazards for pain severity and pain interference with daily living, with exploration of brief pain inventory cutpoints, among women with metastatic breast cancer. J Pain Symptom Manage. 2007;34(4):380-92.

[7]. Sousa FF, Pereira LV, Cardoso R, Hortense P. Escala Multidimensional de Avaliação de Dor (EMADOR). Rev Latino-Am Enfermagem. 2010;18(1):03-10.

[8]. Morete MC, Milson FP. Instrumentos para avaliação da dor em pacientes oncológicos. Rev Dor. 2010;11(1):74-80.

[9]. Silva YB, Pimenta CAM. Análise dos registros de enfermagem sobre dor e analgesia em doentes hospitalizados. Rev Esc Enferm. 2003;37(2):109-18.

[10]. Jost L, Roila F. Management of cancer pain: ESMO Clinical Practice Guidelines. Ann. Oncol. 2010;21(5):257-60.

[11]. Valeberg BT, Rustøen T, Bjordal K, Hanestad BR, Paul S, Miaskowski C. Self-reported prevalence, etiology, and characteristics of pain in oncology outpatients. Eur J Pain. 2008;12(5):582-90.

[12]. Saxena AKR, Kumar S. Management strategies for pain in breast carcinoma patients: current opinions and future perspectives. Pain Pract. 2007;7(2):163-77.

[13]. Ferreira KA, Teixeira MJ, Mendonza TR, Cleeland CS. Validation of brief pain inventory to Brazilian patients with pain. Support Care Cancer. 2011;19(4):505-11.

[14]. Van den Beuken-van Everdingen MHJ, De Rijke JM, Kessels AG, Schouten HC, Van Kleef M, Patijn J. High prevalence of pain in patients with cancer in a large population-based study in The Netherlands. Pain. 2007;132(3):312-20.

[15]. Greenspan JD, Craft RM, LeResche L, Arendt-Nielsen L, Berkley KJ, Fillingim RB et al. Studying sex and gender differences in pain and analgesia: a consensus report. Pain. 2007;132(1):26-45.

[16]. Siegel R, DeSantis C, Virgo K, Stein K, Mariotto A, Smith T, et al. Cancer treatment and survivorship statistics, 2012. CA Cancer J Clin. 2012;62:220-41.

[17]. Schuit KW, Sleijfer DT, Meijler WJ, Otter R, Schakenraad J, Van den Bergh FC, et al. Symptoms and functional status of patients with disseminated cancer visiting outpatient departments. J Pain Symptom Manage. 1998;16(5):290-7.

[18]. Gärtner R, Jensen M-B, Nielsen J, Ewertz M, Kroman N, Kehlet H. Prevalence of and factors associated with persistent pain following breast cancer surgery. JAMA. 2009;302:1985-92

[19]. Mogil JS, Bailey AL. Sex and gender differences in pain and analgesia. Prog. Brain Res. 2010;186:141-57.

[20]. Peng WL, Wu GJ, Sun WZ, Chen JC, Huang AT. Multidisciplinary management of cancer pain: a longitudinal retrospective study on a cohort of end-stage cancer patients. J Pain Symptom Manage. 2006;32:444-52.

[21]. Reyes-Gibby C, Morrow PK, Bennett MI, Jensen MP, Shete S. Neuropathic pain in breast cancer survivors: using the ID pain as a screening tool. J Pain Symptom Manage. 2010;39(5):882-9.

[22]. Alves Nogueira Fabro E, Bergmann A, Do Amaral E Silva B, Padula Ribeiro AC, De Souza Abrahão K, Da Costa Leite Ferreira MG et al. Post-mastectomy pain syndrome: incidence and risks. Breast. 2012;21(3):321-5.

[23]. Irvin W Jr, Muss HB, Mayer DK. Symptom management in metastatic breast cancer. Oncologist. 2011;16(9):1203-14.

[24]. Bardwell WA, Ancoli-Israel S. Breast Cancer and Fatigue. Sleep Med Clin. 2008;3(1):61-71.

[25]. Gulluoglu BM, Cingi A, Cakir T, Gercek A, Barlas A, Eti Z. Factors related to post-treatment chronic pain in breast cancer survivors: the interference of pain with life functions. Int J Fertil Womens Med. 2006;51:75-82. 